\title{
DNA Damage Response-Related Proteins in Gastric Cancer: ATM, Chk2 and p53 Expression and Their Prognostic Value
}

\author{
Hee Eun Lee ${ }^{a, b}$ Nayoung Han ${ }^{a, b}$ Min A Kim ${ }^{a, b}$ Hye Seung Lee ${ }^{b, e}$ \\ Han-Kwang Yang ${ }^{c}$ Byung Lan Lee ${ }^{d}$ Woo Ho Kim ${ }^{a, b}, d$ \\ ${ }^{a}$ Department of Pathology, Seoul National University Hospital, Departments of ${ }^{\mathrm{b}}$ Pathology and $\mathrm{c}$ Surgery and \\ ${ }^{\mathrm{d} C a n c e r}$ Research Institute, Seoul National University College of Medicine, Seoul, and 'Department of Pathology, \\ Seoul National University Bundang Hospital, Seongnam, South Korea
}

\section{Key Words}

Stomach neoplasm $\cdot$ DNA damage response $\cdot$ Ataxia telangiectasia mutated protein - Checkpoint kinase 2 .

Tumor suppressor protein p53 · Survival analysis . Immunohistochemistry

\begin{abstract}
Objectives: The aims of this study were to assess expressions of the DNA damage response (DDR)-related proteins and to investigate their clinical significances in gastric carcinoma. Methods: Two independent cohorts, a training set $(n=524)$ and validation set $(n=394)$, of gastric cancer patients were enrolled. Ataxia telangiectasia mutated (ATM), checkpoint kinase 2 (Chk2), and p53 expressions were examined by immunohistochemistry using tissue microarray. Results: ATM loss, Chk2 loss, and p53 positivity were observed in 21.8, 14.1 , and $36.1 \%$ of the training set, and in $17.3,12.2$, and $35.8 \%$ of the validation set, respectively. In the training set, the aberrant expressions of ATM, Chk2, or p53 were significantly associated with an advanced TNM stage and poor disease-specific survival. This association was verified in the validation set. Chk2 positivity and p53 negativity were significantly related to a prolonged disease-specific survival. Also, patients with nonaberrant expressional levels of all 3 DDR-
\end{abstract}

related proteins had a more favorable outcome than others. Multivariate analyses showed that Chk2 loss and at least 1 aberrant DDR-related protein remained as independent prognostic factors of poor disease-specific survival. Conclusions: This study elucidated the prognostic implications of DDR-related proteins, and suggests that their aberrant expressions play critical roles in the development and progression of gastric cancer.

Copyright $\odot 2013$ S. Karger AG, Basel

\section{Introduction}

Gastric cancer has been reported to be the fourth most common cancer and the second leading cause of cancerrelated death worldwide [1]. More than 930,000 new cases are diagnosed and 700,000 deaths are attributed to gastric cancer annually [2]. At present, surgical resection is the mainstay of treatment, but even after potentially curative resection, the 5-year survival rate is only around $40 \%$ [3-5].

Tumor-node-metastasis (TNM) stage (by UICC/ AJCC) and completeness of surgical excision are considered to be the most powerful prognostic factors in gastric cancer [6]. However, it is not uncommon that gastric can-

\section{KARGER}

E-Mail karger@karger.com

www.karger.com/pat (c) 2013 S. Karger AG, Basel

1015-2008/14/0811-0025\$39.50/0
Dr. Woo Ho Kim

Department of Pathology, Seoul National University College of Medicine

28 Yeongeon-dong, Jongno-gu

Seoul 110-799 (South Korea)

E-Mail woohokim@snu.ac.kr 
cer patients with the same TNM stage pursue quite different clinical courses, and despite continued efforts to identify markers of aggressive disease, no clinically meaningful marker has yet been identified. Thus, the search continues to find prognostic factors of survival, and DNA damage response (DDR)-related proteins are obvious candidate proteins.

When DNA damage occurs, DDR is activated, which includes activation of a cell cycle checkpoint, the initiation of transcriptional programs, and the execution of DNA repair or initiation of apoptosis. The term 'cell cycle checkpoint' refers to control mechanisms that ensure the fidelity of cell division in eukaryotic cells by monitoring the successful completion of upstream events prior to proceeding to the next phase [7]. Defects in DDRs or in mitotic-checkpoint pathways can permit the survival or the continued growth of cells with genomic damage, thereby enhancing the likelihood of malignant transformation [7]. As a result, the cell cycle checkpoint is considered as a strong candidate of the anticancer barrier [8]. The key regulators of checkpoint pathways in mammalian DDR are the ataxia telangiectasia mutated (ATM) and Rad3-related proteins. In particular, ATM, a serine/threonine protein kinase, senses double-strand damage and subsequently activates the DNA damage checkpoint, which leads to cell cycle arrest through the ATM/checkpoint kinase 2 (Chk2)-p53/mouse double minute 2 homolog-p21 pathways $[7,9]$. These findings led us to conjecture that the aberrant expressions of DDR-related proteins, such as ATM, Chk2, and p53, might allow tumorigenic cells to evade normal cell cycle checkpoints, and cause aberrant cell proliferation and survival, increased genomic instability, and ultimately tumor progression. Accordingly, we hypothesized that DDR-related protein alterations might influence tumor progression, and be associated with patient survival in gastric cancer.

In the present study, we evaluated the expressions of ATM, Chk2, and p53 in human gastric carcinoma tissues obtained from two independent cohorts using immunohistochemistry, and followed this with an analysis of associations between their expressions and clinicopathological parameters or patient survival. Also, we hypothesized that the negative regulation of cell proliferation due to DNA damage would not function in tumors with a DDRrelated protein alteration. It is well known that $\mathrm{Ki}-67$ is a cell growth-related antigen [10-12], and thus, we used a $\mathrm{Ki}-67$ labeling index as a surrogate of cell proliferative status. Accordingly, we sought to determine whether expressional alterations in cell cycle checkpoint-related proteins are related with a Ki-67 proliferation index.

\section{Materials and Methods}

\section{Patients}

The files of 524 surgically resected primary gastric carcinoma cases examined at the Department of Pathology, Seoul National University Hospital (Seoul), for the whole of 1995 (training set) [13] and the files of 394 surgically resected primary gastric carcinoma cases examined at the Department of Pathology, Seoul National University Hospital, for the whole of 2004 (validation set) [14] were analyzed. Age, gender, tumor location, WHO and Lauren's classification, pTNM (pathological TNM) stage (by the 7 th UICC/AJCC manual) [1], lymphatic invasion, lymph node metastasis, and distant metastasis were evaluated by reviewing medical charts, pathological records, gross photographs, and glass slides. Median follow-up periods of patients in the training set and the validation set were 97.0 months (range, 1-108) and 49.4 months (range, 0-60), respectively. The cases lost to follow-up and deaths from any other cause other than gastric cancer were regarded as censored data for the analysis of survival rates. No patient received preoperative chemoradiotherapy, and patients with stage II, III, or IV disease received postoperative chemotherapy using a 5-fluorouracil-based regimen (alone, plus mitomycin C, or plus cisplatin). The study protocol was reviewed and approved by the Institutional Review Board of Seoul National University Hospital.

\section{Tissue Array Methods}

Core tissue biopsies ( $2 \mathrm{~mm}$ in diameter) were taken from individual paraffin-embedded gastric carcinomas (donor blocks) and arranged in a new recipient paraffin block (tissue array block) using a trephine apparatus (Superbiochips Laboratories, Seoul). Because we have previously shown excellent agreement between the staining results of different intratumoral areas in gastric carcinoma [13], a core was sampled from each case. An adequate case was defined as a tumor occupying more than $10 \%$ of the core area. Sections $(4 \mu \mathrm{m})$ were cut from each tissue array block, deparaffinized, and dehydrated.

\section{Immunohistochemistry}

Immunohistochemical staining was performed using an automatic immunostainer (Bond-Max, Leica Microsystems, Wetzlar, Germany) according to the manufacturer's instructions. The primary antibodies used were as follows: anti-ATM (Y170; rabbit monoclonal; 1:50; Epitomics, Burlingame, Calif., USA), anti-Chk2 (IMG-336; mouse monoclonal; 1:300; Imgenex, San Diego, Calif., USA), anti-p53 (M7001; mouse monoclonal; 1:200; Dako, Carpinteria, Calif., USA), and anti-Ki-67 (MIB-1; mouse monoclonal; 1: 100; Dako). Cancer cells showing nuclear staining, regardless of the presence of cytoplasmic staining, were considered positively immunostained for ATM, Chk2, p53, and Ki-67. Reduction or lack of staining was restricted to tumor cells; the stromal elements surrounding tumor nests preserved the normal staining pattern, thereby providing an internal control on the same section. Immunostaining of ATM, Chk2, and p53 was scored in a semiquantitative manner considering the proportion of positive cells using a scale of $0-4$ : 0 , no staining; 1 , positive in less than or equal to $10 \%$; 2 , positive in more than $10 \%$, but less than or equal to $33 \% ; 3$, positive in more than $33 \%$, but less than or equal to $66 \%$, and 4 , positive in more than $66 \%$. For Ki-67, areas of highest proliferative activity were searched by scanning tumor sections at low magnification due to the heterogeneous distribution of proliferative tumor 
cells. Tumor cell counting was then performed within these areas at a magnification of $\times 200$. One hundred tumor cells were counted per tumor. The Ki-67 proliferation index was defined as the number of tumor cell nuclei expressing MIB-1 expressed as a percentage of total tumor cell nuclei.

\section{Statistical Analyses}

The survival curves were plotted using the Kaplan-Meier product-limit method, and significance of difference between survival curves was determined using the log-rank test. Multivariate survival analysis was performed using the Cox proportional hazards model. The $\chi^{2}$ test or Fisher's exact test (2-sided) was used to determine the nature of the correlations between antibody expressions and clinicopathological parameters. The relationship between the expression of each DDR protein and cell proliferation index was analyzed using the 2-tailed Student's t test. Results were considered significant when $\mathrm{p}$ values were $<0.05$. All statistical analyses were conducted using the PASW18.0 statistical software program (SPSS, Chicago, Ill., USA).

\section{Results}

\section{DDR-Related Protein Expressions}

The expression levels of ATM, Chk2, and p53 were determined by immunohistochemistry. Representative results of immunohistochemical staining are shown in figure 1. We applied the 'minimum $\mathrm{p}$ value' approach to obtain the cutoff value for each antibody providing the best separation between the groups of patients related to disease-specific survival in the training set. According to this approach, a score of 0 or 1 were regarded as negative while $2-4$ as positive for all three antibodies, and the cutoffs were also applied to the validation set. As a result, in the training set including 524 cases, 114 (21.8\%), 74 (14.1\%), and 189 (36.1\%) showed loss of ATM, loss of Chk2, and p53 positivity, respectively. Also, in a total of 394 cases from the validation set, loss of ATM, loss of Chk2, and p53 positivity were observed in 68 (17.3\%), 48 (12.2\%), and 141 (35.8\%) cases, respectively. When cases were grouped into 'DDR-related protein intact' (DDRRPI; no aberrant expression of ATM, Chk2, or p53) and 'DDR-related protein aberrant' (DDRRP-A; aberrant expression of at least 1 of the 3 proteins), $236(45.0 \%)$ cases in the training set and $184(46.7 \%)$ in the validation set were categorized as DDRRP-I, and $288(55.0 \%)$ cases in the training set and $210(53.3 \%)$ in the validation set as DDRRP-A.

We analyzed the associations among the aberrant expressions of each DDR-related protein, and found that Chk2 loss and ATM loss were significantly correlated ( $p<0.001$, both in the training set and in the validation set) and patients with $\mathrm{p} 53$ negativity tended to have Chk2 loss rather than the intact expression in the validation set $(\mathrm{p}=0.047)$. On the other hand, the aberrant expressions of p53 and ATM in both sets and those of p53 and Chk2 in the training set were not significantly related.

Associations between the Expressions of DDR-Related Proteins and the Ki-67 Proliferation Index

We supposed that damage to DDR-related proteins might cause tumor cell proliferation. Thus, we measured Ki-67 proliferation indices, and sought relations between them and DDR-related protein expressions in the validation set. As was expected, the Ki-67 proliferation index was significantly higher in the $\mathrm{p} 53$-positive group than in the p53-negative group ( $36 \pm 20$ vs. $26 \pm 22 \%$; p < 0.001 ). On the other hand, no statistically meaningful relationships were found between Ki-67 proliferation index and ATM or Chk2 expression. When performing the combination analysis, the DDRRP-A group was found to have a significantly higher Ki-67 proliferation index than the DDRRP-I group $(33 \pm 21$ vs. $26 \pm 22 \%$; $\mathrm{p}=0.001)$.

\section{Associations between the Expressions of DDR-Related}

\section{Proteins and Clinicopathological Parameters}

The correlations found between the expressions of ATM, Chk2, and p53 and clinicopathological features of the gastric cancer specimens are summarized in tables 1 and 2 . In the training set, ATM negativity $(\mathrm{p}<0.001)$, Chk2 negativity $(\mathrm{p}=0.004), \mathrm{p} 53$ positivity $(\mathrm{p}=0.018)$, or DDRRP-A ( $\mathrm{p}<0.001)$ were significantly correlated with a higher TNM stage. In the validation set, ATM negativity $(\mathrm{p}=0.018)$, $\mathrm{p} 53$ positivity $(\mathrm{p}<0.001)$, or DDRRP-A $(\mathrm{p}<0.001)$ was also found to be significantly associated with a higher TNM stage.

\section{Associations between DDR-Related Protein \\ Expressions and Patient Survival}

In order to determine the natures of correlations between survival rate and the expressions of ATM, Chk2, and p53, we used a log-rank test with Kaplan-Meier estimates. Of the 524 patients form the training set, those with ATM positivity $(\mathrm{p}<0.001)$, Chk2 positivity $(\mathrm{p}<$ $0.001)$, p53 negativity ( $\mathrm{p}=0.003)$, or DDRRP-I $(\mathrm{p}<0.001)$ had significantly longer survival times than those with ATM negativity, Chk2 negativity, p53 positivity, or DDRRP-A, respectively (fig. 2). Multivariate Cox hazard models revealed that Chk2 negativity and DDRRP-A were independent biomarkers of poor disease-specific survival (hazard ratio $=1.390,95 \%$ confidence interval, $\mathrm{CI}=1.003-1.927$, and $1.366,95 \% \mathrm{CI}=1.029-1.813$, respectively; table 3 ), after adjusting for the following co- 

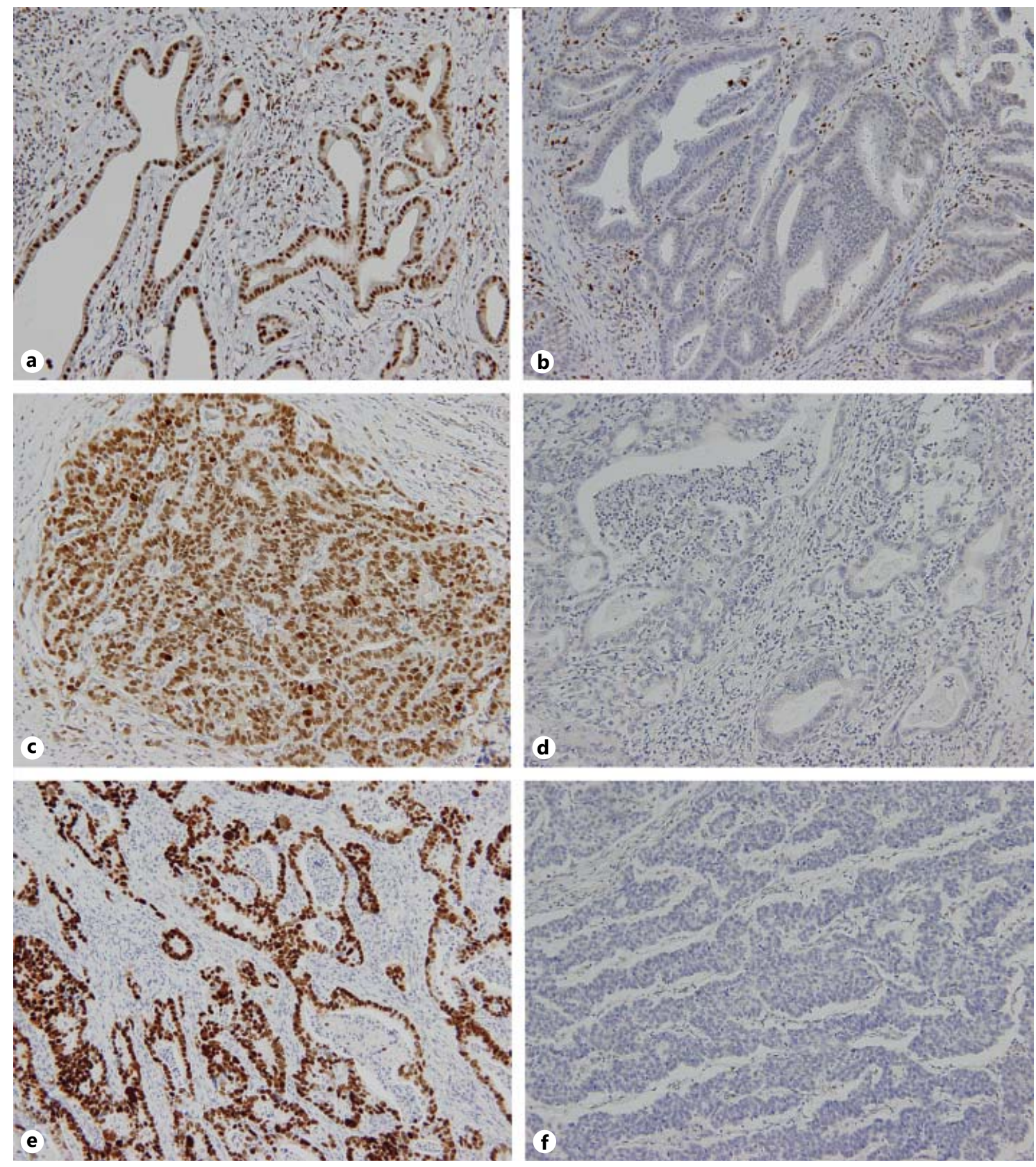

Fig. 1. DDR-related protein expressions in gastric cancer. Immunohistochemical staining for ATM (a, b), Chk2 $(\mathbf{c}, \mathbf{d})$, and p53 (e, f) is shown. Altered expressions of these proteins, loss of ATM (b), loss of Chk2 (d), and overexpression of p53 (e), were observed in $9.9,12.2$, and $35.8 \%$ of the gastric carcinoma cases, respectively. Original magnification $\times 200$.

variates: tumor invasion, lymph node metastasis, and distant metastasis, which were all significant prognostic factors by univariate analyses. However, ATM and p53 were not independent prognostic indicators.

Because prognosis and treatment strategy for patients with TNM stage IV are quite different from those for pa- tients with TNM stages I-III, we divided the patients into groups of stages I-III $(\mathrm{n}=481)$ and of stage IV $(\mathrm{n}=43)$, and performed subgroup analyses. Within the subgroup of stages I-III, ATM positivity ( $\mathrm{p}=0.002)$, Chk2 positivity $(\mathrm{p}=0.001), \mathrm{p} 53$ negativity $(\mathrm{p}=0.003)$, or DDRRP-I $(\mathrm{p}<0.001)$ was significantly associated with a prolonged 
Table 1. Correlations between expressions of ATM, Chk2, or p53 and clinicopathological parameters in gastric carcinomas in the training set

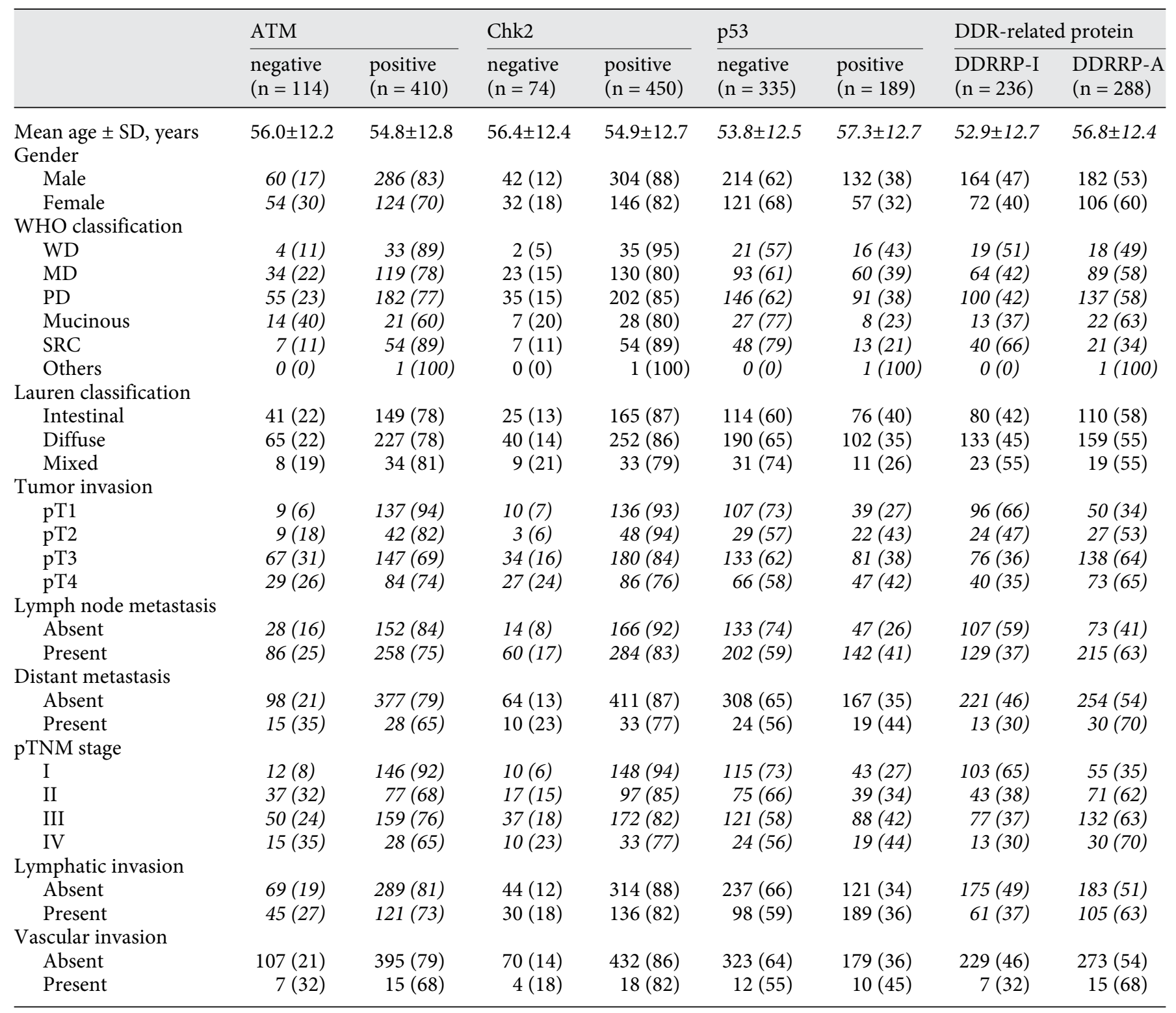

$\chi^{2}$ or Fisher's exact test was used in each analysis except for the analysis of the age factor (Student's t test); data with $\mathrm{p}$ values of statistically significant correlations are indicated in italics; values in parentheses are percentages; SD = standard deviation; WD = well-differentiated tubular adenocarcinoma; $\mathrm{MD}=$ moderately differentiated tubular adenocarcinoma; $\mathrm{PD}=$ poorly differentiated tubular adenocarcinoma; mucinous = mucinous adenocarcinoma; $\mathrm{SRC}=$ signet ring cell carcinoma; $\mathrm{pTNM}=$ pathological tumornode-metastasis.

survival. In the subgroup of stage IV, on the other hand, the survival time was not different according to the expressional status of ATM, Chk2, or p53 expression status.

In the validation set including 394 patients, patients with Chk2 positivity $(\mathrm{p}=0.001)$, p53 negativity $(\mathrm{p}<$ $0.001)$, or DDRRP-I ( $<<0.001)$ showed significantly lon- ger survival times than those with Chk2 negativity, p53 positivity, or DDRRP-A, respectively. Patients with ATM positivity tended to have longer survival times, although it was not statistically significant ( $\mathrm{p}=0.189$; fig. 3 ). Multivariate Cox hazard models revealed that Chk2 negativity and DDRRP-A were independent biomarkers of poor 
Table 2. Correlations between expressions of ATM, Chk2, or p53 and clinicopathological parameters in gastric carcinomas in the validation set

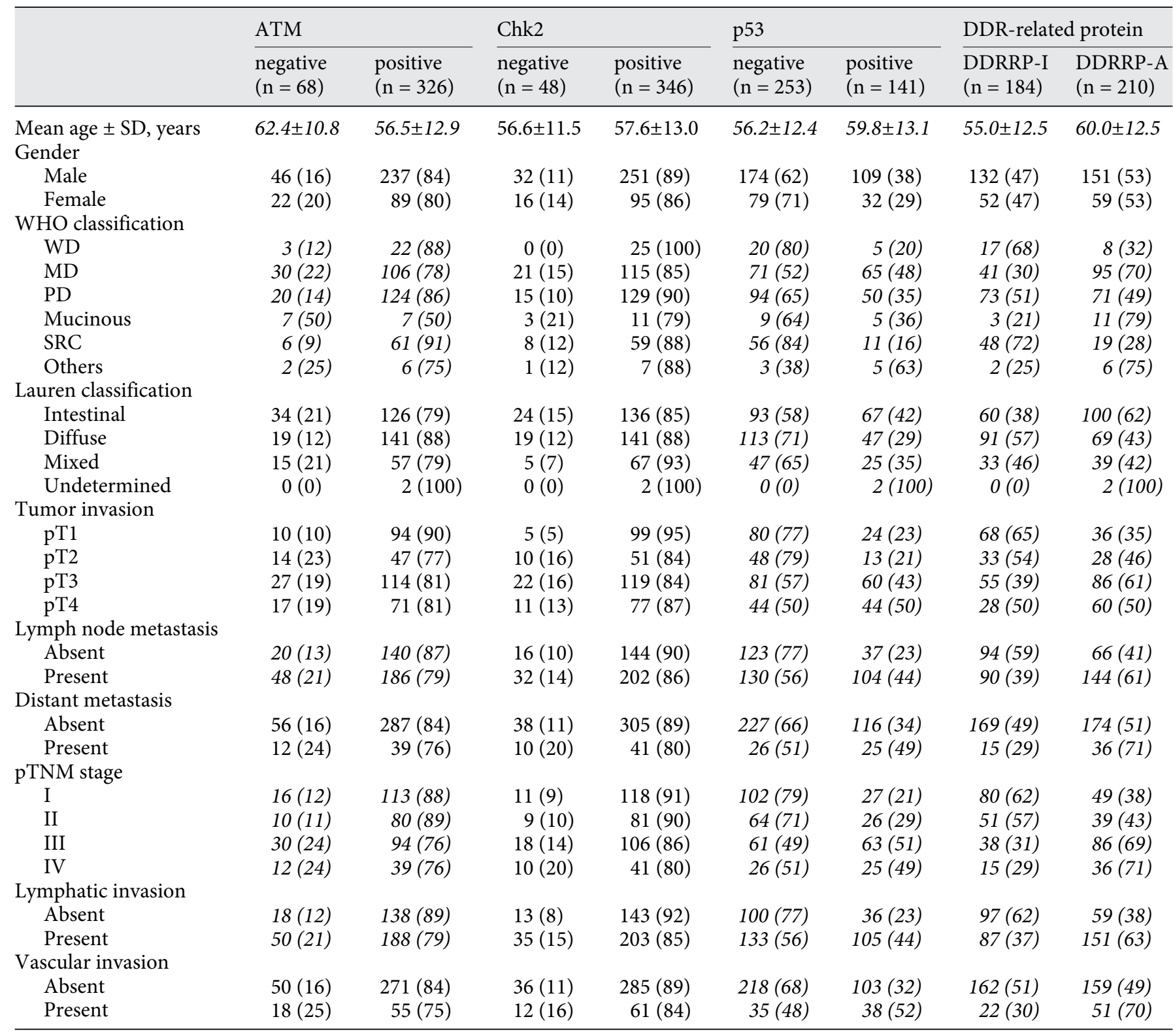

$\chi^{2}$ or Fisher's exact test was used in each analysis except for the analysis of the age factor (Student's t test); data with p values of statistically significant correlations are indicated in italics; values in parentheses are percentages; $\mathrm{SD}=$ standard deviation; WD = well-differentiated tubular adenocarcinoma; $\mathrm{MD}=$ moderately differentiated tubular adenocarcinoma; $\mathrm{PD}=$ poorly differentiated tubular adenocarcinoma; mucinous = mucinous adenocarcinoma; $\mathrm{SRC}=$ signet ring cell carcinoma; $\mathrm{pTNM}=$ pathological tumor-node-metastasis.

survival, after adjusting for tumor invasion, lymph node metastasis, and distant metastasis (hazard ratio $=1.970$, $95 \% \mathrm{CI}=1.245-3.116$, and $1.524,95 \% \mathrm{CI}=1.029-2.257$, respectively; table 3 ). On the other hand, p53 was not found to be an independent prognostic indicator. Within the subgroup of stages I-III $(\mathrm{n}=343)$, Chk2 positivity $(\mathrm{p}=0.043), \mathrm{p} 53$ negativity $(\mathrm{p}<0.001)$, or DDRRP-I $(\mathrm{p}<$ 0.001 ) was significantly associated with better survival, but the ATM expression status was not related to patient survival. In the subgroup of stage IV $(\mathrm{n}=51)$, patients with Chk 2 positivity $(\mathrm{p}=0.005)$ had longer survival times than those with Chk2 negativity, but the expres- 


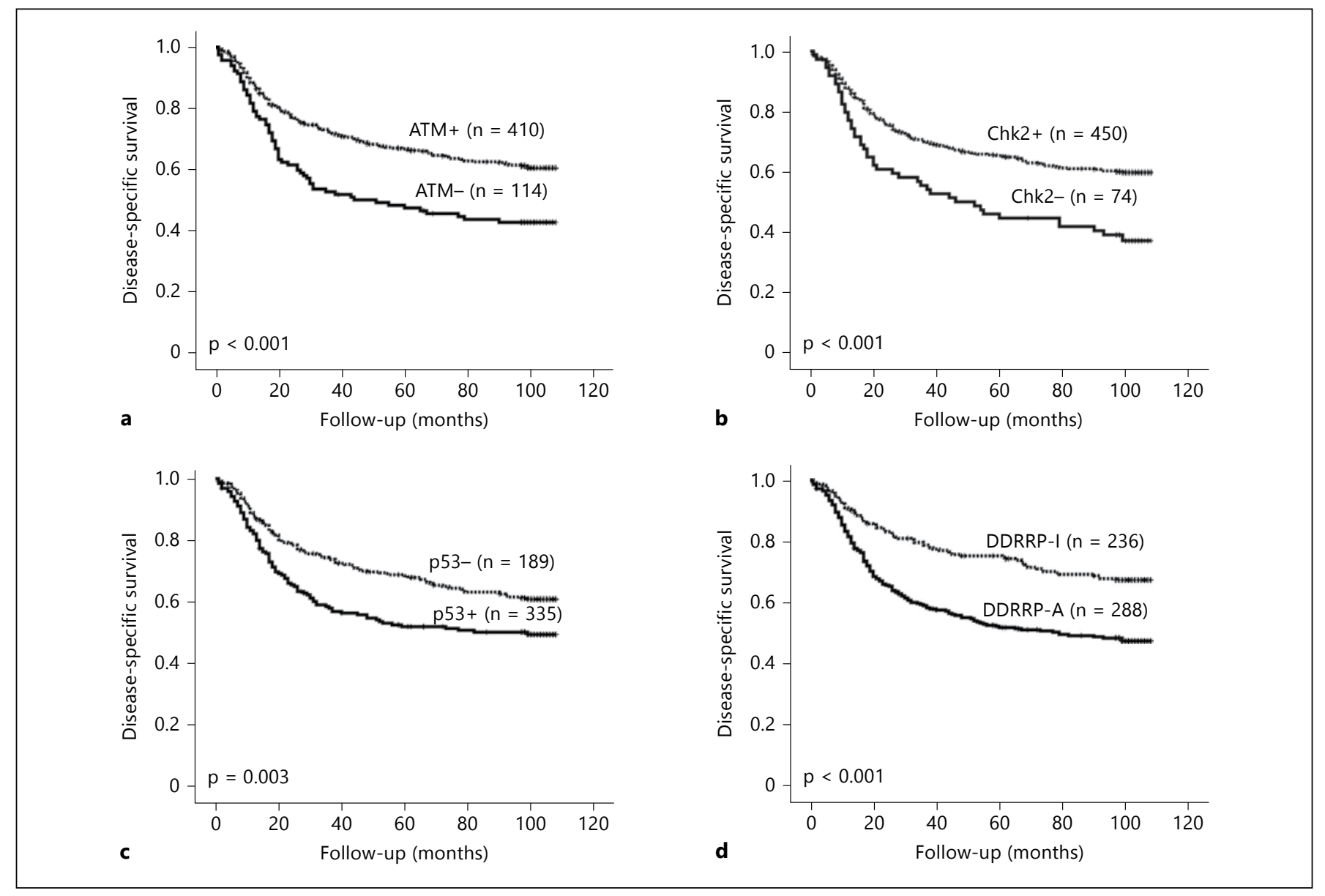

Fig. 2. Kaplan-Meier survival plots for the 524 gastric cancer patients from the training set as a function of DDR-related protein expressions. Patients with ATM negativity (a), Chk2 negativity (b), or p53 positivity (c) showed a significantly shorter survival

sional status of ATM and p53 and combination of the DDR-related protein expression were not associated with patient survival.

\section{Discussion}

In the present study, we determined the expressional status of the DDR-related proteins ATM, Chk2, and p53 in gastric cancer, and correlations between their expressional status and proliferation index, clinicopathological parameters, and patient survival. Alterations in the expressions of DDR-related proteins were found to be associated with an advanced TNM stage and poor prognosis. Specifically, Chk2 loss or the aberrant expression of one or more DDR-related proteins (ATM, Chk2, and time than those with ATM positivity, Chk2 positivity, or p53 negativity, respectively $(\mathrm{p}<0.001, \mathrm{p}<0.001$, and $\mathrm{p}=0.003)$. Also, patients with all 3 DDRRP-I had a significantly longer survival time than those with at least 1 DDRRP-A $(p<0.001 ; \mathbf{d})$. 
Table 3. Multivariate Cox proportional hazard models for the predictors of disease-specific survival

\begin{tabular}{|c|c|c|}
\hline Variables & Hazard ratio & $\mathrm{p}$ value \\
\hline \multicolumn{3}{|l|}{ Training set } \\
\hline \multicolumn{3}{|l|}{ Model 1} \\
\hline ATM expression (positive vs. negative) & $1.301(0.971-1.744)$ & 0.078 \\
\hline Tumor invasion (EGC vs. AGC) & $4.953(2.348-8.985)$ & $<0.001$ \\
\hline Lymph node metastasis (no vs. yes) & $2.811(1.762-4.485)$ & $<0.001$ \\
\hline Distant metastasis (no vs. yes) & $3.473(2.420-4.984)$ & $<0.001$ \\
\hline \multicolumn{3}{|l|}{ Model 2} \\
\hline Chk2 expression (positive vs. negative) & $1.390(1.003-1.927)$ & 0.048 \\
\hline Tumor invasion (EGC vs. AGC) & $4.852(2.491-9.454)$ & $<0.001$ \\
\hline Lymph node metastasis (no vs. yes) & $2.691(1.687-4.293)$ & $<0.001$ \\
\hline Distant metastasis (no vs. yes) & $3.452(2.405-4.953)$ & $<0.001$ \\
\hline \multicolumn{3}{|l|}{ Model 3} \\
\hline p53 expression (negative vs. positive) & $1.169(0.893-1.532)$ & 0.257 \\
\hline Tumor invasion (EGC vs. AGC) & $4.899(2.514-9.549)$ & $<0.001$ \\
\hline Lymph node metastasis (no vs. yes) & $2.685(1.680-4.292)$ & $<0.001$ \\
\hline Distant metastasis (no vs. yes) & $3.471(2.418-4.981)$ & $<0.001$ \\
\hline \multicolumn{3}{|l|}{ Model 4} \\
\hline DDR-related proteins (DDRRP-I vs. DDRRP-A) & $1.366(1.029-1.813)$ & 0.031 \\
\hline Tumor invasion (EGC vs. AGC) & $4.622(2.369-9.018)$ & $<0.001$ \\
\hline Lymph node metastasis (no vs. yes) & $2.683(1.682-4.279)$ & $<0.001$ \\
\hline Distant metastasis (no vs. yes) & $3.479(2.425-4.993)$ & $<0.001$ \\
\hline \multicolumn{3}{|l|}{ Validation set } \\
\hline \multicolumn{3}{|l|}{ Model 1} \\
\hline Chk2 expression (positive vs. negative) & $1.970(1.245-3.116)$ & 0.004 \\
\hline Tumor invasion (EGC vs. AGC) & $8.775(2.122-36.288)$ & 0.003 \\
\hline Lymph node metastasis (no vs. yes) & $6.250(2.854-13.689)$ & $<0.001$ \\
\hline Distant metastasis (no vs. yes) & $5.601(3.794-8.268)$ & $<0.001$ \\
\hline \multicolumn{3}{|l|}{ Model 2} \\
\hline p53 expression (negative vs. positive) & $1.280(0.890-1.840)$ & 0.183 \\
\hline Tumor invasion (EGC vs. AGC) & $9.060(2.186-37.538)$ & 0.002 \\
\hline Lymph node metastasis (no vs. yes) & $5.869(2.677-12.866)$ & $<0.001$ \\
\hline Distant metastasis (no vs. yes) & $5.257(3.564-7.753)$ & $<0.001$ \\
\hline \multicolumn{3}{|l|}{ Model 3} \\
\hline DDR-related proteins (DDRRP-I vs. DDRRP-A) & $1.524(1.029-2.257)$ & 0.036 \\
\hline Tumor invasion (EGC vs. AGC) & $8.434(2.030-35.047)$ & 0.003 \\
\hline Lymph node metastasis (no vs. yes) & $5.902(2.695-12.925)$ & $<0.001$ \\
\hline Distant metastasis (no vs. yes) & $5.325(3.618-7.837)$ & $<0.001$ \\
\hline
\end{tabular}

95\% confidence intervals are indicated in parentheses; EGC = early gastric carcinoma; AGC = advanced gastric carcinoma.

It is evident that although several proteins participate in DDR in a stepwise fashion, they influence by not only one way. In the present study, our combination analysis of the 3 DDR-related proteins suggested that even the aberrant expression of only 1 of the 3 proteins causes an unfavorable clinical course. However, the biological links between genetic alterations in these proteins remain unclear. Further study is needed to reveal the links.

It has been thought that DDR-related proteins were related to chemosensitivity, and as a result, inhibiting these proteins was believed to sensitize tumor cells to can- cer treatments that damage DNA $[15,16]$. Because the patients with gastric cancer in the present study were treated with a chemotherapy regimen containing DNAdamaging agents postoperatively, the expressional status of DDR-related proteins possibly affected the chemoresponse of the tumor. Furthermore, as the prognosis of stage IV patients is more influenced by the chemoresponse, the aberrant expression of the DDR-related proteins could exert an effect toward a favorable clinical outcome through the chemosensitive property. That may be a part of the reason that the expressional status of the 


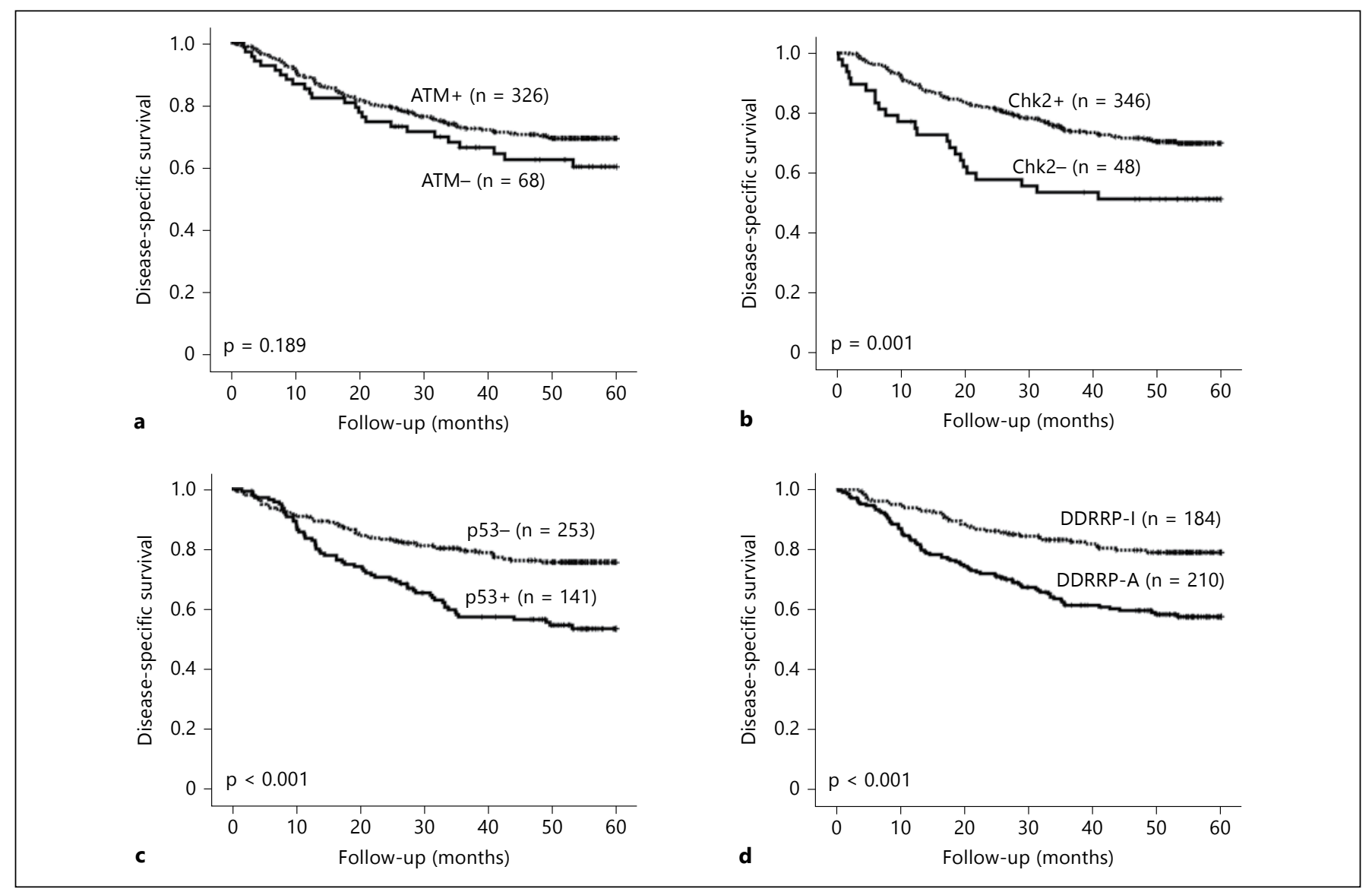

Fig. 3. Kaplan-Meier survival plots for the 394 gastric cancer patients from the validation set as a function of DDR-related protein expressions. ATM expression status was not significantly associated with patient survival (a). Patients with Chk2 negativity (b) or p53 positivity (c) showed a significantly shorter survival time than those with Chk2 positivity or $\mathrm{p} 53$ negativity, respectively $(\mathrm{p}=0.001$ and $\mathrm{p}<0.001)$. Also, patients with all 3 DDRRP-I had a significantly longer survival time than those with at least 1 DDRRP-A $(p<0.001 ; \mathbf{d})$.
DDR-related proteins did not affect patient survival in the subgroup of stage IV patients, whereas their aberrant expressions were significantly related to poor survival in the subgroup of stages I-III. Further study will be needed to elucidate it.

Due to the important role played by ATM in the control of genomic stability, we surmise that defective ATM is likely to be associated with a high cancer risk and a poor prognosis. Furthermore, recent studies have indicated associations between promoter hypermethylation of the $A T M$ gene and reduced postoperative survival in head and neck squamous cell carcinoma, non-small cell lung cancer, and breast cancer [17], and another study reported that the expressional loss of ATM was associated with poor prognosis in colorectal cancer [18]. In ovarian cancer, although ATM and Chk2 protein expressions were not found to be individually related to overall survival, at least one alteration was found to be a negative predictor of overall survival [19]. On the other hand, the expressions of ATM and Chk2 were not found to have predictive value in multimodality-treated esophageal squamous cell carcinoma [20]. With regard to gastric cancer, it has been reported that the presence of a low level of phosphorylated ATM is significantly correlated with poor differentiation, lymph node metastasis, and poor 5-year survival [21]. However, in the present study, no significant survival difference was observed between the ATM-positive and -negative groups, although the ATM-positive group tended to have a longer survival time. This discrepancy between the results may be due to the use of ATM or phosphorylated ATM and to different levels of histological differentiation and TNM stage.

Studies of Li-Fraumeni syndrome have identified germline mutations in the TP53 or CHEK2 genes [22, 23]. 
Mutated Chk2 protein may be functionally defective in terms of its protein-protein interactions and phosphorylation by ATM [23]. Furthermore, it has been reported that patients with Li-Fraumeni syndrome are predisposed to breast cancer, sarcoma, brain carcinoma, and adrenal cortex carcinoma, and that sometimes multiple tumors are identified in the same individual [24]. In addition, it has been reported that cases with high Chk2 protein or mRNA expression tend to have mutated TP53, and in the same study, no relation was found between Chk2 expression and histological differentiation or depth of tumor invasion in gastric cancer [25]. However, to date, no study has revealed any correlation between Chk2 expression and survival in gastric cancer.

Many contradictory results have been reported regarding the prognostic role of p53 in gastric cancer, and whereas some have concluded that aberrant p53 expression is associated with poor survival, others have found no relation [26]. In the present study, patients with aberrant p53 expression were found to have significantly shorter survival times than those with intact p53 expression by the log-rank test. However, p53 expression was not found to be an independent prognostic factor by multivariate analysis.

Although we had shown a good agreement of protein expressions among different tissue cores of each tumor in the previous study [13], intratumoral genetic heterogeneity has become an important issue in cancer therapeutics. Recently, Gerlinger et al. [27] demonstrated extensive intratumoral heterogeneity by exome sequencing, chromosome aberration analysis, and ploidy profiling on multiple spatially separated samples obtained from primary renal carcinomas and associated metastatic sites. Also, they insisted that intratumoral heterogeneity can lead to underestimation of the tumor genomics landscape portrayed from single tumor biopsy samples and may present major challenges to personalized-medicine and biomarker development [27]. Therefore, in order that the DDR-related proteins of our study are clinically used as tumor biomarkers, further investigation regarding intratumoral heterogeneity would be required.

Recently, it was indicated that ATM deficiency sensitizes lymphoid tumor cells to olaparib, a poly(ADP-ribose) polymerase- 1 inhibitor $[28,29]$, and ATM is expected to be a biomarker predicting therapeutic response to olaparib in cancer patients. In addition, at present, clinical trials utilizing olaparib in combination with conventional chemotherapy for advanced gastric cancer patients are being initiated, which is concentrated on patients with ATM protein negative. Accordingly, the accumulation of data on ATM expression in gastric cancer is of importance, and our findings concerning ATM could help progress the clinical applications of targeted therapies.

In conclusion, we elucidated the prognostic implications of the expressions of the DDR-related proteins ATM, Chk2, and p53, in gastric carcinoma. We believe that our findings can be used to aid the prediction of clinical outcome and the definition of patient subgroups with an unfavorable prognosis. In addition, our finding that the prognosis was poor even when only 1 of the 3 proteins was aberrantly expressed emphasizes the critical role of DDR-related proteins in the development and progression of gastric cancer.

\section{Acknowledgement}

This research was supported by a Basic Science Research Program through the National Research Foundation of Korea funded by the Ministry of Education, Science and Technology (2012R1A1A2004648).

\section{References}

1 American Joint Committee on Cancer: Chapter 11: stomach; in Edge SB, Byrd DR, Campton CC, Fritz AG, Greene FL, Trotti A (eds): AJCC Cancer Staging Manual, ed 7. New York, Springer, 2009, pp 117-126.

-2 Parkin DM, Bray F, Ferlay J, Pisani P: Global cancer statistics, 2002. CA Cancer J Clin 2005; 55:74-108.

-3 Hartgrink HH, van de Velde CJ: Status of extended lymph node dissection: locoregional control is the only way to survive gastric cancer. J Surg Oncol 2005;90:153-165.

-4 Hejna M, Wohrer S, Schmidinger M, Raderer M: Postoperative chemotherapy for gastric cancer. Oncologist 2006;11:136-145.
Novotny AR, Schuhmacher C, Busch R, Kat$\tan$ MW, Brennan MF, Siewert JR: Predicting individual survival after gastric cancer resection: validation of a US-derived nomogram at a single high-volume center in Europe. Ann Surg 2006;243:74-81.

6 Ichikura T, Tomimatsu S, Uefuji K, Kimura M, Uchida T, Morita D, Mochizuki H: Evaluation of the New American Joint Committee on Cancer/International Union against Cancer classification of lymph node metastasis from gastric carcinoma in comparison with the Japanese classification. Cancer 1999;86: 553-558.
7 Hartwell LH, Weinert TA: Checkpoints: controls that ensure the order of cell cycle events. Science 1989;246:629-634.

8 Kastan MB, Bartek J: Cell-cycle checkpoints and cancer. Nature 2004;432:316-323.

$\checkmark 9$ Kim HS, Kim MA, Hodgson D, Harbron C, Wellings R, O'Connor MJ, Womack C, Yin X, Bang YJ, Im SA, Lee BL, Kim WH: Concordance of ATM (ataxia telangiectasia mutated) immunohistochemistry between biopsy or metastatic tumor samples and primary tumors in gastric cancer patients. Pathobiology 2013;80:127-137.

10 Levine AJ: p53, the cellular gatekeeper for growth and division. Cell 1997;88:323-331. 
11 Schipper DL, Wagenmans MJ, Peters WH, Wagener DJ: Significance of cell proliferation measurement in gastric cancer. Eur J Cancer 1998;34:781-790.

12 Lee HE, Kim MA, Lee BL, Kim WH: Low Ki67 proliferation index is an indicator of poor prognosis in gastric cancer. J Surg Oncol 2010;102:201-206.

13 Lee HS, Lee HK, Kim HS, Yang HK, Kim YI, Kim WH: MUC1, MUC2, MUC5AC, and MUC6 expressions in gastric carcinomas: their roles as prognostic indicators. Cancer 2001;92:1427-1434.

14 Park JH, Lee BL, Yoon J, Kim J, Kim MA, Yang HK, Kim WH: Focal adhesion kinase (FAK) gene amplification and its clinical implications in gastric cancer. Hum Pathol 2010; 41:1664-1673.

15 Zhou BB, Bartek J: Targeting the checkpoint kinases: chemosensitization versus chemoprotection. Nat Rev Cancer 2004;4:216-225.

16 Ferrao PT, Bukczynska EP, Johnstone RW, McArthur GA: Efficacy of CHK inhibitors as single agents in MYC-driven lymphoma cells. Oncogene 2012;32:1661-1672.

17 Begnami MD, Fregnani JH, Nonogaki S, Soares FA: Evaluation of cell cycle protein expression in gastric cancer: cyclin B1 expression and its prognostic implication. Hum Pathol 2010;41:1120-1127.
8 Grabsch H, Dattani M, Barker L, Maughan N, Maude K, Hansen O, Gabbert HE, Quirke P, Mueller W: Expression of DNA doublestrand break repair proteins ATM and BRCA1 predicts survival in colorectal cancer. Clin Cancer Res 2006;12:1494-1500.

19 Hashiguchi Y, Tsuda H, Inoue T, Nishimura S, Suzuki T, Kawamura N: Alteration of cell cycle regulators correlates with survival in epithelial ovarian cancer patients. Hum Pathol 2004;35:165-175.

20 Sarbia M, Ott N, Puhringer-Oppermann F, Brucher BL: The predictive value of molecular markers (p53, EGFR, ATM, CHK2) in multimodally treated squamous cell carcinoma of the oesophagus. Br J Cancer 2007;97:1404-1408.

21 Kang B, Guo RF, Tan XH, Zhao M, Tang ZB, $\mathrm{Lu} Y Y$ : Expression status of ataxia-telangiectasia-mutated gene correlated with prognosis in advanced gastric cancer. Mutat Res 2008; 638:17-25.

22 Malkin D, Li FP, Strong LC, Fraumeni JF Jr, Nelson CE, Kim DH, Kassel J, Gryka MA, Bischoff FZ, Tainsky MA, et al: Germ line p53 mutations in a familial syndrome of breast cancer, sarcomas, and other neoplasms. Science 1990;250:1233-1238.

23 Srivastava S, Zou ZQ, Pirollo K, Blattner W, Chang EH: Germ-line transmission of a mutated p53 gene in a cancer-prone family with Li-Fraumeni syndrome. Nature 1990;348:747749.

24 Wu X, Webster SR, Chen J: Characterization of tumor-associated Chk2 mutations. J Biol Chem 2001;276:2971-2974.
25 Zhang L, Jia G, Li WM, Guo RF, Cui JT, Yang L, Lu YY: Alteration of the ATM gene occurs in gastric cancer cell lines and primary tumors associated with cellular response to DNA damage. Mutat Res 2004;557:41-51.

26 Hollstein M, Sidransky D, Vogelstein B, Harris CC: p53 mutations in human cancers. Science 1991;253:49-53.

27 Gerlinger M, Rowan AJ, Horswell S, Larkin J, Endesfelder D, Gronroos E, Martinez P, Matthews N, Stewart A, Tarpey P, Varela I, Phillimore B, Begum S, McDonald NQ, Butler A, Jones D, Raine K, Latimer C, Santos CR, Nohadani M, Eklund AC, Spencer-Dene B, Clark G, Pickering L, Stamp G, Gore M, Szallasi Z, Downward J, Futreal PA, Swanton C: Intratumor heterogeneity and branched evolution revealed by multiregion sequencing. $\mathrm{N}$ Engl J Med 2012;366:883-892.

28 Weston VJ, Oldreive CE, Skowronska A, Oscier DG, Pratt G, Dyer MJ, Smith G, Powell JE, Rudzki Z, Kearns P, Moss PA, Taylor AM, Stankovic T: The PARP inhibitor olaparib induces significant killing of ATM-deficient lymphoid tumor cells in vitro and in vivo. Blood 2010;116:4578-4587.

29 Williamson CT, Muzik H, Turhan AG, Zamò A, O'Connor MJ, Bebb DG, Lees-Miller SP: ATM deficiency sensitizes mantle cell lymphoma cells to poly(ADP-ribose) polymerase- 1 inhibitors. Mol Cancer Ther 2010;9:347-357. 